\title{
Editorial
}

\section{Healthcare Worker Stress and Burnout in the time of COVID-19: A Call for Action}

\author{
Ahmed S. A. El Sayed ${ }^{1,2}$ \\ ${ }^{1}$ Department of Surgery, Faculty of Medicine, Alzaiem Alazhari University, Khartoum North, Sudan \\ ${ }^{2}$ Director, Alazhari Health Research Center, Khartoum, Sudan
}

ORCID:

Ahmed S. A. El Sayed: https://orcid.org/0000-0001-7422-7169

Corresponding Author: Ahmed S. A. El Sayed; email:

asaelsayed@hotmail.com

Received 22 August 2021

Accepted 08 September 2021

Published 30 September 2021

Production and Hosting by Knowledge E

(c) Ahmed S. A. El Sayed. This article is distributed under the terms of the Creative

Commons Attribution

License, which permits unrestricted use and redistribution provided that the original author and source are credited.

Editor-in-Chief:

Prof. Mohammad A. M. Ibnouf
The COVID19 pandemic has come as a shock to the whole world. Since it first became apparent in Wuhan, China [1] in late 2019, till June 9, 2021, 174 million people were infected, and 3.76 million people had died [2]. The risk of infections among healthcare workers has been observed to be higher than in the general community [3], and this risk is carried on to people in their households [4]. The WHO has devised a protocol to help in this respect [5].

As of June 9, 2021, Sudan had recorded 36,004 proven infections and 2,711 deaths [6]. Moreover, 109 deaths were reported in doctors between January 14, 2020 and March 12, 2021 [7]. However, in this article, it is argued that this is only the tip of the iceberg. It is a well-established fact that healthcare workers suffer from an undue amount of stress and burnout [8], and our yet unpublished data show Sudan is not an exception. The current COVID 19 pandemic has further exacerbated this situation by increasing the stress levels among healthcare workers, as shown by data from countries as diverse as China [9], Italy [10], and Saudi Arabia [11]. However, in Sudan, the stress levels are expected to be comparatively more due to the current economic situation in the country with rampant inflation [12] and other consequent problems such as frequent power cuts.

These effects of work-related stress, burnout, and other mental health consequences have been shown by previous epidemics (e.g., Middle East Respiratory Syndrome) to have long-term consequences [11, 13, 14]. These long-term consequences, if not mitigated, would ultimately lead to decreased work productivity and less efficiency in the workplace [15]. Unfortunately, in developing countries, a barrier to identifying and dealing with these mental health consequences is the stigma associated with these conditions [16]. This social stigma forces these individuals to either keep them a secret or withdraw from society [17]; as a consequence, they may not disclose their symptoms to healthcare professionals or even to their family and relatives [18]. Another barrier is that even if the individual does not have a stigma, there is, unfortunately, a lack 
of adequately trained individuals to treat them as it has been reported that for severe mental health disorders, there is a deficiency in treatment of 76-90\% in low- and middleincome countries (LMICs), respectively [19].

From the above, it becomes evident that in LMICs, prevention is the way forward. This is easier said than done, as proven by a 2015 Cochrane review that looked at published literature until then and concluded that that there was low-quality evidence that neither personal nor organizational interventions had any effect, if at all, in reducing stress [20]. This review concluded that organizational interventions need better focus on the reduction of specific stressors. Researchers are continuing to look at possible solutions, and recently there have been some positive results [21].

From the perspective of Sudan and in the current pandemic, some more recent literature looks more relevant. The most relevant of these was the Coping with COVID study [22], which mainly pointed out that for healthcare workers feeling valued by higher hospital authorities led to lower stress. This was confirmed by a subsequent work [23]. However, further data from the same group that has published the Coping with COVID study group [24] showed that in a large United States-based study of nearly 21,000 healthcare workers from 42 different organizations, 38\% had anxiety/depression, 49\% had burnout, and $50 \%$ felt not valued. The authors suggested that organizations should explore the causes of this (e.g., increased workload), and after that, organizations should consider targeted interventions such as peer support programs and changes in care infrastructure to facilitate support. The authors further developed a conceptual model portraying potential contributors and mitigators of stress and burnout, as shown in Figure 1.

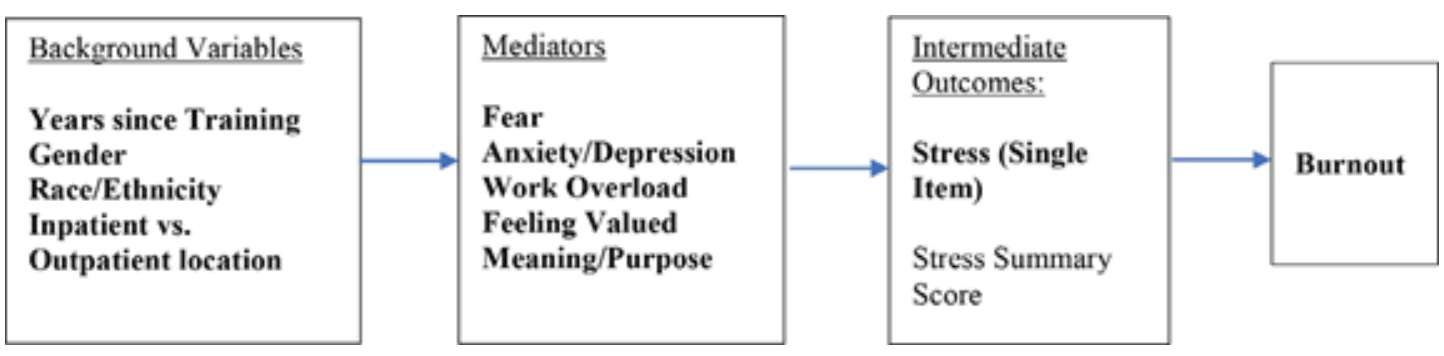

Figure 1: Potential contributors and mitigators of stress and burnout [24].

Following the above, similar interventions can easily be done in Sudan after taking into consideration the local culture, as shown in the Saudi Arabian study [11], which showed stress and fear of contracting COVID19 was particularly high amongst those who had vulnerable elderly family members at home which is highly likely to be true in our similar circumstances. 
Finally, a firm action should be taken on the unquestionably present scourge of stress and burnout among Sudanese healthcare workers by identifying the risk factors and mitigating them.

\section{References}

[1] Sun, J., He, W., Wang, L., et al. (2020). COVID-19: Epidemiology, evolution, and crossdisciplinary perspectives. Trends in Molecular Medicine, vol. 26, no. 5, pp. 483-495.

[2] John Hopkins University \& Medicine. (n.d.). John Hopkins University coronavirus resource center. Retrieved from: https://coronavirus.jhu.edu/map.html

[3] Nguyen, L. H., Drew, D. A., Graham, M. S., et al. (2020). Risk of COVID-19 among front-line health-care workers and the general community: a prospective cohort study. Lancet Public Health, vol. 5, no. 9, pp. e475-e483.

[4] Shah, A. S. V., Wood, R., Gribben, C., et al. (2020). Risk of hospital admission with coronavirus disease 2019 in healthcare workers and their households: nationwide linkage cohort study. BMJ, vol. 371, m3582.

[5] World Health Organization. (2020). Protocol for assessment of potential risk factors for 2019-novel coronavirus (COVID-19) infection among health care workers in a health care setting. Retrieved from: https://www.who.int/publications/i/item/protocolfor-assessment-of-potential-risk-factors-for-2019-novel-coronavirus-(2019-ncov)infection-among-health-care-workers-in-a-health-care-setting

[6] John Hopkins University \& Medicine. (n.d.). John Hopkins University corona virus resource center - regional data (Sudan). Retrieved from: https://coronavirus.jhu.edu/ region/sudan

[7] Ibnouf, M. A. M. (2021). University staff and student protection from COVID-19: strategic measures for teaching and learning in resource-limited setting. Sudan Journal of Medical Sciences, vol. 16, no. 1, pp. 1-4.

[8] National Academies of Sciences Engineering and Medicine. (2019). Taking action against clinician burnout: a systems approach to professional wellbeing. Washington, DC: The National Academies Press. Retrieved from: https://www.nap.edu/catalog/25521/taking-action-against-clinician-burnout-asystems-approach-to-professional

[9] Lai, J., Ma, S., Wang, Y., et al. (2020). Factors associated with mental health outcomes among health care workers exposed to coronavirus disease 2019. JAMA Network Open, vol. 3, no. 3, e203976. 
[10] Rossi, R., Socci, V., Pacitti, F., et al. (2020). Mental health outcomes among frontline and sec- ond-line health care workers during the coronavirus disease 2019 (COVID19) pandemic in Italy. JAMA Network Open, vol. 3, no. 5, e2010185.

[11] Alenazi, T. H., BinDhim, N. F., Alenazi, M. H., et al. (2020). Prevalence and predictors of anxiety among healthcare workers in Saudi Arabia during the COVID-19 pandemic. Journal of Infection and Public Health, vol. 13, no. 11, pp. 1645-1651.

[12] OCHA. (2021). SUDAN inflation hits 342 per cent in March. Retrieved from: https: //reports.unocha.org/en/country/sudan/card/6yvup9AF6K/

[13] Lee, S. M., Kang, W. S.,Cho, A.-R., et al. (2018). Psychological impact of the 2015 MERS outbreak on hospital workers and quarantined hemodialysis patients. Comprehensive Psychiatry, vol. 87, pp. 123-127.

[14] Preti, E., Di Mattei, V., Perego, G., et al. (2020). The psychological impact of epidemic and pandemic outbreaks on healthcare workers: rapid review of the evidence. Current Psychiatry Reports, vol. 22, no. 8, p. 43.

[15] Stavroula, L., Griffiths, A., and Cox, T. (2003). Work organisation and stress: systematic problem approaches for employers, managers and trade union representatives. Protecting Workers' Health Series No. 3.

[16] Thornicroft, G., Alem, A., and Dos Santos, R. A. (2010). WPA guidance on steps, obstacles and mistakes to avoid in the implementation of community mental health care. World Psychiatry, vol. 9, no. 2, pp. 67-77.

[17] Link, B. G., Cullen, F. T., Struening, E. L., et al. (1989). A modified labeling theory approach in the area of mental disorders: an empirical assessment. American Sociological Review, vol. 54, no. 3, pp. 400-423.

[18] Shibre, T., Negash, A., Kullgren, G., et al. (2001). Perception of stigma among family members of individuals with schizophrenia and major affective disorders in rural Ethiopia. Social Psychiatry and Psychiatric Epidemiology, vol. 36, no. 6, pp. 299303.

[19] Patel, V., Maj, M., Flisher, A. J., et al. (2010). Reducing the treatment gap for mental disorders: a WPA survey. World Psychiatry, vol. 9, no. 3, p. 169.

[20] Ruotsalainen, J. H., Verbeek, J. H., Marine, A., et al. (2015). Preventing occupational stress in healthcare workers [Review]. Cochrane Database of Systematic Reviews, vol. 4, CD002892.

[21] Niks, I., de Jonge, J., Gevers, J., et al. (2018). Work stress interventions in hospital care: effectiveness of the DISCovery method. International Journal of Environmental Research and Public Health, vol. 15, no. 2, p. 332. 
[22] Linzer, M., Stillman, M., Brown, R., et al. (2021). Preliminary report: US physician stress during the early days of the COVID19 pandemic. Mayo Clinic Proceedings: Innovations, Quality \& Outcomes, vol. 5, no. 1, pp. 127-136.

[23] Feingold, J. H., Peccoralo, L., Chan, C. C., et al. (2021). Psychological impact of the COVID-19 pandemic on frontline health care workers during the pandemic surge in New York city. Chronic Stress. Retrieved from: https://doi.org/10. 1177\{\%\}2F2470547020977891

[24] Prasad, K., McLoughlin, C., Stillman, M., et al. (2021). Prevalence and correlates of stress and burnout among U.S. healthcare workers during the COVID-19 pandemic: a national cross-sectional survey study. EClinical Medicine, vol. 35, 100879. 